\title{
The Privilege of Attending Early Childhood Education (ECE)
}

\author{
Arsendy Senza ${ }^{1, *}$ George Adam Sukoco Sikatan ${ }^{1}$ Yusuf Faisal Martak ${ }^{1}$ \\ ${ }^{I}$ School of Department Monitoring, Evaluation, Research and Learning, Innovation for Indonesia's School Children \\ (INOVASI) Program, Jakarta, Indonesia \\ "Corresponding author. Email: senzaarsendy@gmail.com
}

\begin{abstract}
A growing body of evidence has found that Early Childhood Education (ECE) gives longer-term beneficial effects on a student's cognitive ability. Unfortunately, in developing countries, and especially other low-resource environments, too few children have the privilege to attend ECE. Using INOVASI's ${ }^{1}$ large-scale longitudinal datasets, this study presents the inequality issue of ECE participation and its effect on students' learning outcomes in Indonesia. The findings suggest that participation rates in ECE are significantly higher in more developed provinces in Indonesia. ECE is mainly dominated by students from higher socio-economic backgrounds, and those with more well-educated and engaged parents. ECE participation rates also have an impact on student learning achievement, with children participating in ECE having substantially better outcomes compared to their counterparts. Furthermore, students who did not enroll in ECE may lose almost two years of learning. The evidence puts forth in this paper suggests that the Indonesian government needs to improve access to ECE and its quality particularly for less advantaged children in remote areas. Inattention to this issue will only produce wider inequality in education and learning outcomes.
\end{abstract}

Keywords: ECE, quality, inequality

\section{INTRODUCTION}

In the last three decades, Early Childhood Education (ECE) - well known as PAUD in the Indonesia contexthas become a major priority for the development agenda of many governments around the World (Ministry of Education, 2012). Skills and learning competencies developed in early childhood affect students' future success in learning and the labour market, making it a crucial time to accumulate human capital as well as a vulnerable time to be left behind (Lyon, 1998; International Labour Organization [ILO], 2012). The long-term beneficial effects of an ECE program are well documented. An ECE program may significantly enhance student's school readiness, achievement and completion while decreasing delayed enrolment, grade-repetition, dropout, substance abuse and also crime rates (United Nations Children's Fund [UNICEF], 2019; Reynolds, 2015). Lack of access to ECE will only stretch the achievement gap and limit opportunities for those from a lower socio-economic background.

The study has found that those who require ECE the most, get it the least (Naudeau, Kataoka, Valerio, Neuman, \& Elder, 2010). In developing countries, good quality ECE may not be accessible to the majority of poor children, and this is also the case in Indonesia. Indonesia's Ministry of Education and Culture (MoEC) has an agenda to strengthen the access of ECE in its 2015-2019 strategic action plans, however bringing the agenda into practice is not a simple task. Since 2015, the rough participation rate (APK) of Indonesian ECE for years 3-6 has always been below the target. In addition, there is a gap in ECE Gross Participation Rates (APK) between urban and rural areas. Given the importance of attending ECE, Indonesia provides an interesting case, examining the widening gap between the rich and the poor. The main objective of this study is to investigate the inequality issue of ECE participation and its effect on students' learning achievement in Indonesia. It then investigates relevant literature to give a brief description of Indonesian ECE policy, accessibility and quality, explain study methods and finding, look at the study limitations, before providing a discussion and recommendations.

\section{LITERATURE REVIEW}

\subsection{ECE Policy, Accessibility and Quality}

ECE development in Indonesia started in 2001, when MOEC formed a new department devoted to early childhood development. This department's main duties are

\footnotetext{
1 The data referenced here is from Survei Inovasi Pendidikan dan Pembelajaran Indonesia (SIPPI). We would like to thank the Australian Government funded Innovation for Indonesia's School Children (INOVASI) program, where the author was engaged with the program's Monitoring, Evaluation, Research and Learning (MERL) team. INOVASI seeks to understand how to improve student learning outcomes in literacy and numeracy in diverse schools and districts across Indonesia. Please note that all opinions and perspectives expressed in the article are those of the author, not INOVASI.
} 
to create strategies and advocate for the importance of ECE to the public as well as provide additional resources to the community regarding ECE services. A major second development was in 2003 and 2004, when ECE was included in key strategic policy documents such as in the National Education System Act and MOEC's strategic action plans (Denboba, Hasan, \& Wodon, 2015, p. 1). The consideration to make ECE a foundation for Indonesia's education system led to further ambitious policy strategy and direction in 2008, with the development of ECE national standards by the National Education Standards Board (Denboba et al., 2015, p. 2).

Despite the ambitious regulation, converting the strategy into concrete practice proved challenging. The number of ECE schools has increased significantly in the last several years $(85,499$ ECE in $2015 / 2016$ to 201,067 in 2018), however, the enrolment rate of ECE remains below the government target (see Figure 1). The absence of powerful policy to provide free ECE and make it compulsory contributes to this problem. MOEC's data on ECE for 2018 shows that 201,067 ECE are operating, however, only approximately $20 \%$ of them are accredited. Among the ECE, the majority are private $(196,913)$ and only a small minority are public $(4,154)$. In addition to lack of access, the quality of ECE is still considerably low. Recent government data suggests that from 656,210 ECE teachers, only $59 \%(386,146$ teachers $)$ of those hold a bachelor's degree. This number may be overvalued as there is no specific data on the number of teachers who hold a bachelor's degree with an ECE major (MOEC ECE Statistic Data, 2019). Furthermore, the quality of infrastructure and ECE school facilities are still below the government standard (Ministry of Education and Culture Act, 2014). For instance, in Semarang, Tamaya (2015) found that many schools still have difficulty reaching a minimum movement ratio standard for every child in the class $\left(3 \mathrm{~m}^{2}\right)$, number of land area $\left(300 \mathrm{~m}^{2}\right)$ and facility standards such as having a school health unit and playground.

\footnotetext{
${ }^{2}$ SIPPI is an instrument which constructed by INOVASI's program to identify and analyse the best practice of education which suitable with the local context

${ }^{3}$ Will mentioned as SLA. SLA is an instrument to evaluate the effectiveness of treatment which consists of both literacy and numeracy test for students in first grade until six grades
}

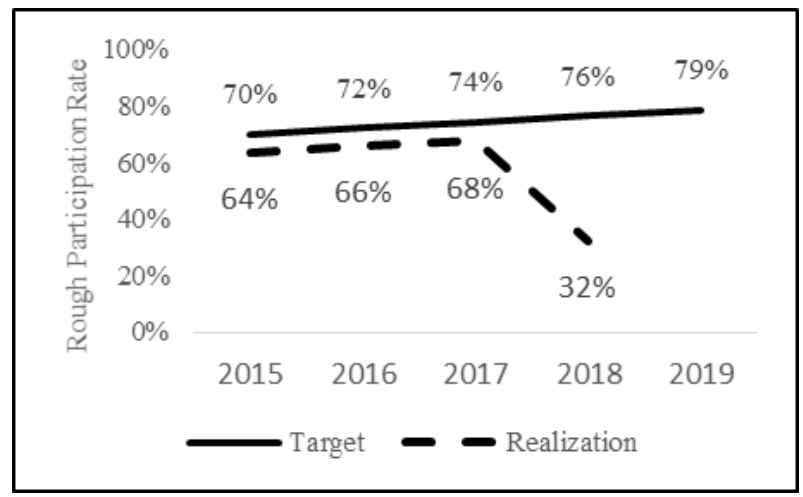

Source: Ministry of Education and Culture, 2019 Figure 1 Gross participation rates (APK) of ECE in Indonesia

\section{METHODOLOGY}

The study used survey data conducted by the Inovasi untuk Anak Sekolah Indonesia (INOVASI) program. INOVASI is a partnership program between the Australian and Indonesian governments. Working directly with MOEC, INOVASI tries to understand what does and does not work to improve student learning outcomes in diverse classrooms across Indonesia. Areas of focus include basic literacy, numeracy and inclusive education. Currently INOVASI works in four partner provinces in Indonesia (East Java, North Kalimantan, West Nusa Tenggara, and East Nusa Tenggara).

\subsection{Instrument and Respondents}

Data used in this study derived from Survei Inovasi Pendidikan dan Pembelajaran Indonesia (SIPPI) ${ }^{2}$. For the purposes of this study, only data from Student Learning Achievement (SLA) ${ }^{3}$ and the SIPPI Household Survey were used. There are two types of SLA tests, the basic test and the comprehension test. Only students who passed the basic test could take the comprehension test.

The basic literacy test is designed to estimate students' ability in understanding letters of the alphabet, syllables, and words, while the basic numeracy test assessed students' ability in number identification and quantity discrimination. The main purpose of both the literacy and numeracy comprehension tests is to evaluate the extent of student critical thinking and reading/numeracy comprehension skills $^{4}$.

\footnotetext{
${ }^{4}$ The cognitive domain of this test is adapted from the study conducted by PIRLS, TIMMS and EGRA. For the finalization process, this instrument asked for a review of language expert from ACER.
} 
Regarding the SIPPI Household Survey, only the parental survey was used for the purposes of this study. It provides important information related to the student's household socio-economic status, parental educational background, and their subjective evaluation of their involvement in the students' learning process.

This study drew on observations, as well as complete data on student learning outcomes ${ }^{5}$ and parental survey data. The resulting sample included 9,474 students and their parents in 17 INOVASI partner districts across four provinces.

\subsection{Method of Analysis}

Statistical descriptive method was used to measure the different aspects (i.e. student's learning outcome and their parental background) between students who have attended ECE and their non-ECE counterparts. The comparison focuses on their household background and learning achievement, including parents' education and learning involvement, socio-economic status and student's literacy and numeracy scores.

\section{FINDINGS}

\subsection{Household Background-Living Area and Socio-economic Level}

In the first section, researchers compared ECE participation rate based on student's living area and their socio-economic status. Regarding the living area, those who live in a more developed province tend to have a higher level of ECE participation compared to students who live in less developed areas. The ECE enrollment rate in East Java is $97 \%$, followed by NTB and North Kalimantan, $83 \%$ and $75 \%$ respectively. The lowest ECE participation can be found in NTT which only has a $62 \%$ participation rate (see Figure 2).

In terms of socio-economic level, researchers divided the level into three quintiles; the higher the quintile, the higher the status. The findings showed that socio-economic status goes hand in hand with student's participation rate in ECE. Households at the top of the quintile ( $3^{\text {rd }}$ Quintile) have the highest participation rate in ECE compared to households at the bottom of the quintile ( $2^{\text {nd }}$ and $1^{\text {st }}$ quintiles) which accounts for $97 \%, 90 \%$, and $66 \%$, respectively.

\subsection{Parental Background}

This section discusses the parental background measured by parental education and involvement in the student's learning process.

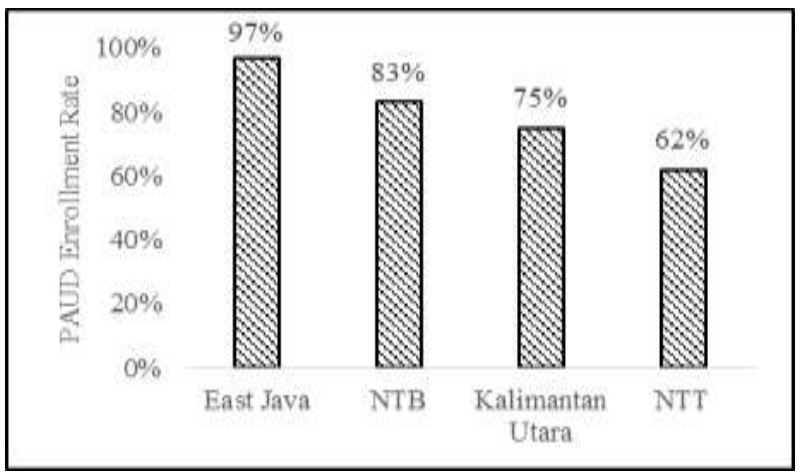

Figure 2 PAUD enrollment rate

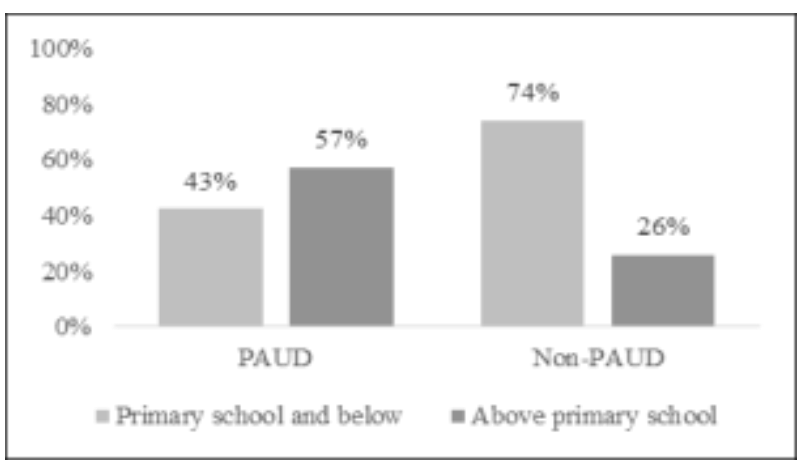

Source: INOVASI Dataset, 2019, t-test p-value $=0.0000$

Figure 3 PAUD enrollment rate and parent's educational background

The result showed that there was a significant association between parent's education and PAUD enrollment rate. Children who participated in ECE are more likely to have parents with higher educational backgrounds. For instance, $57 \%$ of students who attended ECE have parents with at least junior high school degrees, while the majority of nonECE students (74\%) have parents with only a primary school degree or less (see Figure 3).

Secondly, we found that parental involvement may play a substantial role in improving ECE enrollment rates. The involvement is measured through two ways, namely parental subjective evaluation and their children's evaluation. The finding showed that children who participated in ECE are more likely to have parents that engage actively in their learning. The result was consistent from both parents' and students' perspectives. For example, $45 \%$ of students who attended ECE reported that their parents actively help them to study while only $28 \%$ of nonECE students reported a similar response.

\footnotetext{
${ }^{5}$ Students in the $1^{\text {st }}, 2^{\text {nd }}$, and $3^{\text {rd }}$ grade
} 


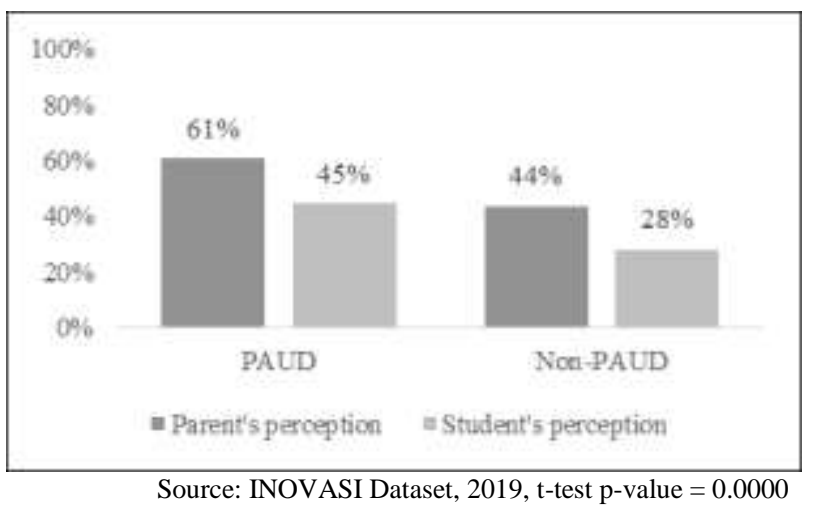

Figure 4 PAUD enrollment rate and parent's active involvement in children learning

\subsection{Student's Learning Outcomes}

It has been found that students who have participated in PAUD, on average, have higher learning outcomes as compared to students who did not enroll in PAUD (The California Department of Education, 2005; Slaby Loucks, \& Stelwagon, 2005). In examining INOVASI basic literacy test scores, $65 \%$ of the first group (ECE attendees) passed the basic literacy test, while only $31 \%$ of the second group (non-ECE) passed the test. The result was consistent for both female and male students.

Regarding the grade, even when they are in the same grade, the data showed that students with ECE background tended to have a higher passing rate than students who did not enroll in ECE. Students of $1^{\text {st }}$ grade, $2^{\text {nd }}$ grade, and $3^{\text {rd }}$ grade who previously attended ECE had a passing rate of $44 \%$, $69 \%$, and $88 \%$, respectively. Conversely, students who did not enroll in ECE had a passing rate of only $0.1 \%, 30 \%$, and $48 \%$, respectively in each class. Those numbers also showed that the passing rate of the $1^{\text {st }}$ grade students who enrolled in ECE was similar to the $3^{\text {rd }}$ grade students who did not complete ECE.

The improved student learning outcomes for those students with an ECE background can also be observed in the comprehension test. Students' participation in ECE had a significantly higher average score on the test than their counterparts who did not participate in ECE. In the literacy test, the average score of the first group was 67.4 while the second group only scored 52.4. A similar trend was also seen in the numeracy comprehension test. Students enrolled in PAUD had better average score of 47.2 whilst those who did not go to PAUD only scored 33.2.

\section{DISCUSSION}

The analysis revealed important findings regarding the unequal access of ECE and its adverse impact on students' learning achievement. Similar to previous studies, the access of ECE was still significantly tied to children's socio-economic background (Bridges, Fuller, Rumberger, $\&$ Tran, 2004). Despite the fact that the overall participation rate was still below the government's official target, students from higher social status backgrounds had a significantly higher enrollment percentage than their peers from less privileged communities (Mitchell \& MeagherLundberg, 2017; Skattebol, 2016).

A previous `study found that ECE participation in formal or nonformal institutions was vary considerably by region and wealth in which the rate for the richest is almost four times higher than the poorest (National Development Planning Agency, 2013). This study identified some variables which may contribute to the ECE enrollment, such as economic status, parents' education and their involvement in their kids' schooling.

The ECE enrollment rate gap between students from welloff and poor backgrounds also seems to contribute to unequal student learning outcomes in INOVASI's partner locations. For instance, using the basic literacy test, it can be seen that primary school students who did not attend ECE had significantly lower performance compared to their counterparts who attended ECE. Further analysis has also shown that third grade students who did not attend ECE tended to have similar results to first grade students who did attend. It can be argued that the absence of ECE can lead to a two-year learning loss for primary school students.

Further investigation is needed to explore why attending PAUD would substantially increase students' literacy skills. Current literature on this issue has provided some potential explanations for results described above. According to Jung and Hasan (2014), although most children did not do formal learning in ECE, participating in ECE has improved their executive functions, measured by card sorting test. In addition to this cognitive benefit, ECE has been known to prepare students, both emotionally and psychologically, for primary school. These skills play a significant role in helping children adapt to the learning process in primary school (Crehan, 2018). Without the ECE experience, children would not be ready to learn to read and do math as well as socialize with peers in a more complex school environment.

Despite those useful findings to understand the inequality of ECE enrollment in Indonesia, this analysis can still be improved through a number of ways. Firstly, it should be noted that sample in this study was only selected from 17 districts in four provinces in Indonesia. In order to get a more comprehensive result, researchers may need to include more provinces in the analysis. Secondly, literature from other contexts showed further evidence that PAUD enrollment benefits children as they grow older. However, this kind of analysis is still limited in the Indonesian context. Therefore, this study can be improved to explore the long-term impact of PAUD participation. Lastly, as this study is limited only in exploring family factors, particularly parental variables, it is important to investigate the role of relevant district policy on ECE access.

\section{CONCLUSION}

ECE in Indonesia is still not universal. Although in some parts, it is freely and readily available, parents should still 
spend personal funding in order to enroll their children in ECE in other areas. For those who cannot afford the fee, they will choose not to enroll their children. Hence, our first recommendation is that the Indonesian government should promote low cost, if needed, it is free of charge of ECE, particularly for less privileged children. In addition to improving access, the quality of the PAUD institutions should be improved. A recent study from Baker, Gruber, \& Milligan (2019) indicated that participating in low quality ECE will bring negative outcomes for school-age children. This means that making ECE universal will not be enough if quality remains low, the outcomes will still remain low. A second recommendation relates to action needed to bring non ECE children's skills 'up to par'. The Indonesian government should ensure that teachers in lower grades have the necessary skills to effectively teach students how to read and do math as well as help students adapt to their school environment. If students fail to master these skills, the negative implications will be long term.

It is important to note that the level of parental engagement tends to be higher when children are still young. Therefore, the government should also work together with parents to maximize the benefits of attending ECE. Effort should be made to not only raise awareness with parents of the importance of ECE but should also improve their capacity to engage in their children's learning. Without these key elements, the long-term impact could be severe for learning outcomes.

\section{REFERENCES}

Baker, M., Gruber, J., \& Milligan, K. (2019). The longrun impacts of a universal child care program.

American Economic Journal: Economic Policy, 11(3), $1-26$.

Bridges, M., Fuller, B., Rumberger, R., \& Tran, L. (2004). Preschool for california's children: promising benefits, unequal access. Policy Brief 04-3. Policy Analysis for California Education, PACE (NJ1), 1-12.

California Department of Education. (2005). Preschool for all: A first-class learning initiative.

Retrieved from http://www.cde.ca.gov/

Crehan, L. (2018). Cleverlands. London: Unbound.

Denboba, A., Hasan, A., \& Wodon, Q. (2015). Early childhood education and development in Indonesia: An assessment of policies using SABER. Washington DC: World Bank.

International Labour Organization (ILO). (2012). Right beginnings: Early childhood education and educators. Geneva: International Labour Organization
Jung, H., \& Hasan, A. (2014). The impact of early childhood education on early achievement gaps. Jakarta: World Bank.

Lyon, G. R. (1998). Overview of reading and literacy initiatives. Bethesda, MD: National Inst. of Child Health and Human Development.

Ministry of Education and Culture. (2019). PAUD

Statistic Data 2018-2019. Jakarta: Ministry of Education and Culture

Ministry of Education. (2012). New zealand ministry of education annual report 2010. New Zealand: Ministry of Education

Mitchell, L., \& Meagher-Lundberg, P. (2017). Brokering to support participation of disadvantaged families in early childhood education. British Educational Research Journal, 43(5), 952-967.

National Development Planning Agency. (2013). Early childhood development strategy study in Indonesia. Jakarta: National Development Planning Agency.

Naudeau, S., Kataoka, N., Valerio, A., Neuman, M. J., \& Elder, L. K. (2010). Investing in young children: An early childhood development guide for policy dialogue and project preparation. Washington DC: The World Bank.

Reynolds, A. (2015). Small investment in children's education yields big results. Washington DC: National Institute of Child Health and Human Development.

Skattebol, J. (2016). Taking advantage of early childhood education and care: the priorities of lowincome families in their children's early years. Families, Relationships and Societies, 5(1), 109-125.

Slaby, R., Loucks, S., \& Stelwagon, P. (2005). Why is preschool essential in closing the achievement gap?. Educational Leadership and Administration: Teaching and Program Development, 17, 47-57.

Tamaya. (2015). Analisis implementasi standar sarana prasarana PAUD dikaji berdasarkan permendikbud Nomor 137 Tahun 2014 tentang standar nasional paud. Semarang: Universitas Negeri Semarang.

United Nations Children's Fund. (2019). A world ready to learn: Prioritizing quality early childhood education. New York: United Nations Children's Fund. 